\title{
Why Does the Ethnic and Socio-economic Composition of Schools Influence Math Achievement? The Role of Sense of Futility and Futility Culture
}

\author{
Orhan Agirdag ${ }^{1}$, Mieke Van Houtte ${ }^{1}$ and Piet Van Avermaet ${ }^{2}$
}

\begin{abstract}
Although a number of studies in many countries have investigated the impact of the ethnic and socio-economic composition of schools on academic performance, few studies have analyzed in detail how and why compositional features matter. This article presents an examination of whether pupils' sense of futility and schools' futility culture account for the impact of ethnic and socio-economic status (SES) composition of schools on the academic achievement of their pupils. Multilevel analyses of data based on a survey of 2,845 pupils (aged 10-12 years) in 68 Flemish primary schools revealed that higher proportions of immigrant and working-class pupils in a school is associated with lower levels of math achievement in both immigrant and native Belgian pupils. However, by analyzing at a deeper level, by taking control variables into account, our study found that the ethnic composition of the school no longer had a significant effect on pupils' achievement, while the SES composition still did. Most importantly, our results indicated that the remaining impact of SES composition can be explained by pupils' sense of futility and schools' futility culture. The implications of these findings for educational policy are discussed.
\end{abstract}

\section{Introduction}

Ever since James Coleman and his team published their influential study on the impact of the ethnic and socio-economic school composition on pupils' academic achievement in 1966, the issue has continued to be debated. Indeed, the issue goes beyond purely academic speculation as it is directly related to policies concerning school segregation. While most previous studies on this topic have been conducted in the United States with secondary school students (Bankston and Caldas, 1998; Rumberger and Palardy, 2005; Ryabov and Van Hook, 2007), the issue has become increasingly popular among European sociologists, as indicated by a growing number of publications in the European Sociological Review directly or indirectly related to the impact of school composition on academic performance (Van der Slik
Driessen and De Bot, 2006; Boado, 2007; Fekjaer and Birkelund, 2007; Biedinger, Becker and Rohling, 2008; Brännström, 2008; Kauppinen, 2008) and furthermore there is a growing body of research in different countries with primary school pupils (Strand, 1997; Driessen, 2002; Van der Slik et al., 2006; Dumay and Dupriez, 2008). With a few exceptions, these studies have demonstrated that the socio-economic composition of primary schools is related to academic achievement, that is, pupils going to schools with a higher share of children from a higher socio-economic background were found to perform academically better. There is less consensus when it comes to the impact of ethnic school composition: while some authors suggest that a higher concentration of ethnic minority and immigrant pupils is related to lower academic performance (Driessen, 2002; Dumay and Dupriez, 2008), others do not find a

\footnotetext{
${ }^{1}$ Department of Sociology, Research Group CuDOS, Ghent University, Korte Meer 5, 9000 Gent, Belgium,

${ }^{2}$ Director of the Centre for Diversity and Learning, Ghent University, Sint-Pietersnieuwstraat 49, 9000 Gent, Belgium. ${ }^{\star}$ Corresponding author. Fax: +32.(0)9.264.69.75; Email: orhan.agirdag@ugent.be
} 
significant relationship between ethnic school composition and academic achievement, in particular when individual socio-economic status (SES), ethnic background and previous academic achievement are taken into account (Van der Slik et al., 2006; Fekjaer and Birkelund, 2007).

These studies, among others, have made considerable contributions to our knowledge of the influences of ethnic and socio-economic school composition on academic achievement. However, less is known about how and why these compositional features are influential, despite the fact that understanding this fully should be an essential part of the foundation of educational policy. For instance, much of the research that has suggested that the ethnic and socio-economic composition of a school exert an influence on pupils' academic achievement has failed to investigate why this might be. However, if further research was conducted with the aim of identifying the mediating processes that explain why certain school compositions affect academic performance, then policymakers might be able to improve student achievement without desegregation, by focusing on these processes. Nevertheless, if those mediating processes that influence the success of students are found to be inherently linked to the compositional features of the school environment, then efforts to change the composition of the school should be advocated (Rumberger and Palardy, 2005). This artilce presents our attempt to improve our understanding of the impact of socio-economic and ethnic school composition by exploring the mediating role of the highly neglected concepts of sense of futility (Brookover and Schneider, 1975) and futility culture (Van Houtte and Stevens, 2008, 2010). Before we discuss the importance of these concepts, we will briefly describe our study setting.

\section{Study Setting}

This study was conducted in Flanders, the Dutchspeaking region of Belgium. Belgium is an exceptionally interesting case study for the impact of school segregation as previous studies have pointed out that socioeconomic and ethnic school segregation is very high there compared to other Western countries (Jacobs, Rea and Teney, 2009). The unusually high unequal distribution of ethnic minority (immigrant) and working class students between schools is linked to both historical evolution and to Belgian educational policy. First, after World War II, Belgium rapidly developed into a multicultural society comprised of immigrants from Southern Europe, Turkey and North Africa. Immigration was restricted by the government in 1973, however the influx of immigrants continued via family reunification and matrimonial migration (Sierens et al., 2006; Agirdag, 2009). Given that these immigrants usually lived in particular districts within the larger cities in which industries were located, this led to a concentration of immigrant students in certain schools, namely, in those that traditionally enrolled native Belgian working-class children. As these schools attracted greater numbers of immigrant students, they became confronted with so-called 'white flight', whereby native Belgian parents decided to enroll their children in other schools because of the increasing number of immigrant students. Higher-educated and economically better-situated immigrant parents tended to follow the example of native Belgian parents as well. Thus we are dealing with schools that are segregated along both socio-economic and ethnic lines (Sierens et al., 2006; Van Houtte and Stevens, 2009).

Second, this exceptionally high level of school segregation is related to the specific educational policy of free parental choice. The Belgian educational system is characterized by the principle of freedom of education, which means that the assignment of students to schools is not regulated (e.g. by place of residence) within the public education sector. This freedom of school-choice allows parents to choose or avoid schools with a certain composition. As middle class parents have more resources, they tend to avoid schools with a high share of working class and immigrant pupils, even if these schools are situated in their immediate neighbourhood. As a result, ethnic and socio-economic school segregation is very high in Belgium (Sierens et al., 2006; Van Houtte and Stevens, 2009).

In Belgium, schools with a high share of ethnic minority and working class pupils are commonly named 'concentration schools', which is a pejorative term. In the public discourse, a 'concentration school' is almost a synonym for a school with low instruction quality and weak academic performance. While these 'concentration schools' are segregated along both socio-economic and ethnic lines, the concentration of ethnic minority pupils is considered especially problematic (Sierens et al., 2006). However, in Belgium, there is very little scientific evidence about the impact of ethnic and/or socio-economic school composition on academic achievement (for a preliminary analysis of the PISA 2006 data for secondary schools in Belgium, see Jacobs et al., 2009) and there are even fewer empirical explanations of why school composition affects academic performance. Hence it is vital to address these issues to achieve a better understanding of the potential harms of socio-economic and/or ethnic school segregation. 


\section{Sense of Futility and Futility Culture}

An essential part of the socialization process takes place in the school context, since children spend almost half their waking hours at school. As such, contextual school conditions are likely to influence pupils' beliefs, attitudes, and feelings toward schooling. In particular, compositional school characteristics are likely to have an impact because these compositional features of schools not only determine with whom pupils in a given school interact, but also influence the relationships between pupils and teachers (Thrupp, 1999; Van Maele and Van Houtte, 2010). Pupils' disposition toward schooling or educational success, in turn, can be expected to have an effect on their academic performances (Bourdieu and Passeron, 1990). In other words, pupils' dispositions are likely to mediate the impact of ethnic and socio-economic school composition on achievement. Here we are dealing with the well-known Bourdieuian Structure-Disposition-Practice (SDP) scheme (Bourdieu, 1977), which is frequently used as an explanation of why socio-economic and ethnic differences at the individual pupil level have an impact on academic achievement (for an overview see Nash and Lauder, 2010), whereas the SDP scheme is widely neglected when it comes to the impact of contextual school level differences in socio-economic and ethnic composition.

Here, we consider the concept of sense of futility as a potential dispositional variable that might account for the impact of school composition. Sense of futility refers to students' belief that they have no control over their educational success and their feelings that the school system is working against them (Brookover and Schneider, 1975; Brookover et al., 1978). We expect that children in schools with an higher share of working class and ethnic minority pupils are more likely to develop a sense of futility because these 'concentration schools' are in general little esteemed and their pupils are expected to fail (see section above on 'Study Setting'). Even teachers in such schools expect their students to be less teachable (Thrupp 1999; Van Maele and Van Houtte, 2010). Hence pupils in schools with a high share of working class and immigrant children are likely to internalize these negative beliefs which may result in a higher sense of futility. Recent empirical evidence points in this direction: Van Houtte and Stevens $(2008,2010)$ have shown that sense of futility is more prevalent in schools with a lower mean SES composition. Moreover, these authors make a clear distinction between sense of futility (at pupil level) and pupils' common feelings of futility within schools, for which they introduced the concept of 'school futility culture'. Both sense of futility and futility culture have been shown to have a negative impact on pupils' study involvement. In this article, we adopt this distinction between pupil-level sense of futility and school-level futility culture. We will examine whether these variables potentially account for the effect of ethnic or socio-economic school composition on academic achievement.

It should be noted that the concept of sense of futility is distinct from the social-psychological concepts of self-esteem and educational aspirations. To illustrate this, compare a typical item from the sense of futility measurement ('people like me will never do well in school even though we try hard') with an item from the widely used Rosenberg Self-Esteem questionnaire ('in general, I am content with myself, see Rosenberg and Simmons, 1972). The most important difference is that while sense of futility refers to group based beliefs (i.e. 'students like me'), the self-esteem measurement refers only to the individual ('I am ...'). As such, the sense of futility is a more appropriate way to conceptualize group based dispositions as described in the work of Pierre Bourdieu (1977). Moreover variables such as self-esteem and educational aspirations are unable to account for the negative impact of schools with a higher concentration of ethnic minority and working-class pupils, as there is firm empirical evidence that in such schools pupils' self-esteem and educational aspirations are even higher than in schools with a higher share of ethnic majority and middle-class pupils (Gray-Little and Hafdahl, 2000; Verkuyten and Thijs, 2004; Frost, 2007).

Against this background, we can express our research questions in the following-more operational-terms:

1. Does the socio-economic and/or ethnic composition of schools have an effect on pupils' academic achievement?

2. If they do, do these compositional features still have an effect on achievement when we control for individual-level and school-level variables?

3. If they still do, do sense of futility and futility culture account for the impact of socio-economic and/or ethnic composition of schools on academic achievement?

\section{Methods}

\section{Sample}

We use data gathered during the academic year 2008-2009 from 2,845 pupils in a sample of 68 primary schools in Flanders, as part of the Segregation in Primary Education in Flanders (SIPEF) project. Multistage 
sampling was conducted. In the first instance, in order to encompass the entire range of ethnic composition, we selected three cities in Flanders that had relatively ethnically diverse populations. Second, using data gathered from the Flemish Educational Department, we chose 116 primary schools within these selected cities and asked them to participate: 54 per cent of them agreed to do so. To avoid selection bias, these schools were selected on one of the independent variables (King, Keohane and Verba, 1994), that is, we selected the school according to their ethnic composition, as this information was made available by the Flemish Educational Department. Our aim was to select one third of the schools with a low concentration of immigrants $(<10$ percent), one third with a medium concentration (between 10 and 50 percent) and one third with a high concentration (between 50 and 100 percent). Because the non-response was not related to the ethnic composition of schools, the schools in the SIPEF-data set encompassed the entire range of ethnic composition, from those with almost no immigrant pupils to some composed entirely of immigrants.

In all the schools that agreed to participate, our research team conducted a questionnaire with all the fifth-grade pupils present during our visit. If there were fewer than 30 fifth-grade pupils present then we also surveyed all the sixth-grade pupils as well. The questionnaire consisted of two parts and lasted two hours. In the first hour, we gathered information on the background variables and non-cognitive variables (e.g. parental support, sense of futility, etc...). In the second hour, an academic achievement test was conducted. Given the time limitation, we could not test all subjects. We focused on math achievement, since a large proportion of the respondents are not native speakers of Dutch and math tests are less linguistically biased than more linguistically challenging subjects such as reading (Abedi, Hofstetter and Lord, 2004). To assure that the questions were curriculum-based, the school principals were asked to approve the test. Two schools were removed from the analysis because these schools could not confirm that the test was curriculum-based. This reduced the number of schools in our data set to 66 and the number of pupils to 2,787 .

\section{Research Design}

Because the data set was made up of a clustered sample of pupils nested within schools and involved data at different levels (pupil- and school-level), the use of hierarchical linear modeling (multilevel modeling) is most appropriate (SAS PROC MIXED, Singer, 1998). Since some studies have pointed out that the impact of ethnic and/or socio-economic school composition might differ for native and ethnic minority pupils (Szulkin and Jonsson, 2007), we carried out each analysis separately for native Belgian $(N=1,453)$ and immigrant children $(N=1,350)$.

We began by estimating the unconditional models to determine the amount of variance in academic performance that occurs among schools. Then, in the first models, we examined the effects of ethnic and SES composition. As there is a high correlation between SES and ethnic school composition (i.e. between the proportion of working class pupils and immigrant pupils at school level; Pearson $r=0.88$ ), including both variables in the same model could cause multicollinearity problems. Therefore, following Dumay and Dupriez (2008), we decided to include both compositional variables in different sets of models. At this stage, these compositional effects should be interpreted very carefully, especially regarding policy implications. As noted by Manski (1993, 2000), it is vital to take into account correlated or selection effects when examining contextual effects. A correlated or selection effect occurs when pupils with similar characteristics tend to be clustered in similar schools. For instance, when SES composition is not significantly related to pupils' academic achievement anymore after taking pupil level SES into account, then socio-economic school segregation per se should not be a policy concern. Therefore in the next models, to rule out selection effects, we control for variables that have been demonstrated to be related to pupils' academic achievement (Thrupp, Lauder and Robinson, 2002). At the individual level we controlled for grade, gender, individual SES, previous achievement, parental support, and individual SES. For immigrant students we also controlled for ethnicity. At the school level we controlled for school sector and school size ('Variables' section). In case compositional variables were still related to pupils' academic achievement, in the next models we entered students' sense of futility and schools' futility culture to examine whether they account for the impact of school composition.

In variables measured by means of a scale, responses were imputed for missing values by way of item correlation substitution: a missing value for one item is replaced by the value of the item correlating most highly with that item (Huisman, 2000). For the sake of comparability across different models, cases with remaining missing values were removed from the analysis. For native Belgian pupils 80 cases were removed from the analysis, returning the total to 1,352 , and for immigrant pupils 144 cases were removed, returning their number to 1,206 (Table 1). 
Table 1 Descriptive statistics for variables: frequencies, means (for continuous variables) and proportions (for categorical variables) and standard deviations (SD)

\section{Natives \\ $N \quad$ Mean or per cent (SD) \\ Immigrants Mean or per cent (SD)}

\begin{tabular}{lcccc}
\hline School level & & & & \\
$\quad$ Ethnic composition: per cent immigrants & 60 & $47.936(31.982)$ & 66 & $52.669(33.999)$ \\
SES composition: per cent blue-collar & 60 & $36.212(21.854)$ & 66 & $38.505(22.289)$ \\
School sector (private) & 60 & 53.33 & 66 & 51.52 \\
School size & 60 & $229.217(108.237)$ & 66 & $225.485(104.528)$ \\
Futility culture & 60 & $2.078(0.274)$ & 66 & $2.092(0.279)$ \\
Individual level & & & & \\
$\quad$ Math achievement & 1352 & $44.109(10.025)$ & 1206 & $39.064(10.521)$ \\
Sense of futility & 1352 & $1.929(0.761)$ & 1206 & $2.216(0.842)$ \\
Grade (sixth) & 1352 & 27.29 & 1206 & 34.99 \\
Gender (girl) & 1352 & 52.22 & 1206 & 52.16 \\
Grade retention & 1352 & 15.53 & 1206 & 39.22 \\
Parental support & 1352 & $4.516(0.542)$ & 1206 & $4.476(0.579)$ \\
SES & & & & \\
$\quad$ Blue-collar & 1352 & 17.38 & 1206 & 63.85 \\
$\quad$ Technicians & 1352 & 17.09 & 1206 & 13.60 \\
$\quad$ Self-employed & 1352 & 6.14 & 1206 & 8.37 \\
$\quad$ Lower white-collar & 1352 & 25.30 & 1206 & 9.78 \\
$\quad$ Service class & 1352 & 34.10 & & 4.39 \\
Ethnicity & - & - & 1206 & 28.03 \\
$\quad$ Turkish & - & - & 1206 & 32.67 \\
$\quad$ Moroccan & - & - & & 39.30 \\
$\quad$ 'Other' & - & - & & \\
\hline
\end{tabular}

Source: SIPEF-data.

\section{Variables}

\section{Ethnic origin}

Because the analyses were performed separately for native and immigrant pupils, it is important to explain how we distinguished between these two groups. The principal criterion was the birthplace of the pupils' grandmothers. If these data were missing, we considered parents' birthplaces instead, as most non-native pupils in Flanders are second- or third-generation immigrants (Agirdag, 2010). As is common practice, and in line with the official Flemish definition of non-native groups, students of Western European origins were considered to be of native descent. As such, we created a dichotomous variable $(0=$ native, $1=$ immigrant $)$ so that 47.73 per cent of our respondents are categorized as immigrant.

\section{Outcome}

The dependent variable in our analysis is math achievement, measured by a test developed by Dudal and Deloof (2004), which is based on Flemish educational attainment levels outlined for students in the fifth grade of their primary education. The test consists of 60 items, covering elementary arithmetic, problem solving, fractions, point numbers, and long division. The test yielded a Cronbach's alpha of 0.91 . In our data, on a theoretical range from 0 to 60 , native pupils achieved on average $44.11(\mathrm{SD}=10.03)$ and immigrant pupils 39.06 $(\mathrm{SD}=10.52$; Table 1$)$.

Individual level variables

Our research concentrated on fifth- and sixth-grade pupils. Therefore, in 2009, most of the respondents were aged 11 ( $\sim 49$ per cent) or 12 ( $\sim 36$ per cent). Given the high correlation between age and grade (Cramer's $\mathrm{V}=0.64 ; P<0.001$ ), we had to choose one of these two variables to enter into the model. Because the sample was unbalanced in terms of grade, we opted for the grade (Table 1).

The sample was equally divided with respect to gender, with around 52 per cent of the respondents being female $($ male $=0$, female $=1$; Table 1$)$. 
Our data did not include a direct measure of the previous achievement of pupils. Initially, our intention was to measure previous achievement using pupils' Grade Point Average (GPA) from previous years. However, many schools did not provide their pupils' GPA, so we were unable to include previous GPA in our model. As an alternative way of measuring this, we asked pupils whether they had to repeat a year in the past. This is because retention is regarded as a reliable indicator of poor academic achievement (Alexander, Entwisle and Dauber, 1994). Table 1 indicates that almost 16 per cent of native pupils in our sample and 39 per cent of immigrant pupils had had to repeat a year in the past (Table 1).

Parental support was measured using a seven-item scale with five answer categories, ranging from 'absolutely do not agree' (scored 1) to 'completely agree' (scored 5) (Brutsaert, 2001). Two sample items are: 'My parents accept me as I am' and 'I feel that my parents do not care much about me' (reversed). This scale yields a Cronbach's alpha of 0.73 . With respect to parental support, immigrant pupils had a mean score of $4.48(\mathrm{SD}=0.58)$ and native students $4.52(\mathrm{SD}=0.54$; Table 1).

We measured the family SES of the pupils by assessing the occupational prestige of the father and mother (Erikson, Goldthorpe and Portocarero, 1979). The highest-prestige occupation of the parents was used as an indicator of the SES of the family. We identified five distinct groups, which are hierarchically ordered with regard to social status: (i) unemployed and blue-collar workers, (ii) technicians and supervisors, (iii) small proprietors and self-employed workers, (iv) lower-grade white-collar employees, and (v) higher-grade professionals and entrepreneurs. Table 1 clearly shows that immigrant pupils are significantly more represented in the lower socio-economic groups.

For immigrant students, we also we controlled for ethnicity, based on the birthplace of elders (see above). Because the group sizes of the different ethnic groups in our data are rather low, we only distinguished three groups: we created two dummy variables for the two numerically largest immigrant groups in Belgium, i.e. (i) Turks (28 per cent) and (ii) Moroccans (33 per cent) and other immigrant pupils are categorized as (iii) 'others' (39 per cent; Table 1). This last category is used as the reference category in the multilevel analyses.

Pupils' sense of futility is measured according to the sense of futility scale (Brookover et al., 1978). The four items are 'People like me will not have much of a chance to do what we want to in life,' 'People like me will never do well in school, even though we try hard,' 'At school, students like me seem to be unlucky,' and 'Achievement at school is just a matter of luck.' Each item has five responses ranging from 'absolutely do not agree' (scored 1) to 'completely agree' (scored 5 ). While this scale yielded a relatively low Cronbach's alpha (0.62), an explanatory factor analysis revealed that there was one underlying dimension for this scale, explaining 47.46 per cent of the variance.

\section{School-level variables}

The ethnic composition of schools is measured by the proportion of non-Western immigrant respondents in any one school in our database. On average, the proportion of immigrant pupils is $52.66 \mathrm{per}$ cent $(\mathrm{SD}=33.99)$, ranging from 2.63 to 100 per cent. In six of the schools in our data set there were no native pupils, reducing the number of schools with native pupils to 60 (Table 1).

The socio-economic composition of the school was calculated by aggregating the individual family SES of pupils. Specifically, this was done by calculating the proportion of pupils from a blue-collar working-class background. On average, the proportion of pupils from a blue-collar background is 38.50 per cent $(S D=22.29)$, ranging from 3.94 to 96.15 per cent.

At a school level, we also controlled for school sector and school size. The school sector variable was split between 32 public schools (municipal and state schools; score 0 ) and 34 private schools (score 1). We determined school size from the total number of pupils, using data gathered from the Flemish Educational Department. The number of pupils varied from 91 in the smallest school to 526 in the largest. The schools had an average of 223 pupils ( $\mathrm{SD}=104.03$; Table 1 ).

Two level of a schools' futility culture is measured by aggregation of individual level scores of sense of futility. A customary aggregation strategy is the calculation of the means of individual level responses of the students within each school (Stern, 1970). However, the aggregation has to be reliable and represent something truly shared at the school level (Glick, 1985). To examine whether futility culture was truly shared within schools, we calculated the mean rater reliability, based on the intraclass correlation (ICC) of a one-way analysis of variance, with the formula: ICC $=$ (Between Mean Square-Within Mean Square)/Between Mean Square). It is only legitimate to speak of a futility culture when the ICC is higher than 0.60 (Shrout and Fleiss, 1979). The sense of futility scale yielded an ICC of 0.73 . This means that feelings of futility are more shared within schools than they are shared between schools, indicating that a futility culture exists at school level. The mean futility culture for the average school was 2.09 $(S D=0.278)$, and it correlated significantly with the 
ethnic composition (Pearson $r=0.53 ; P<0.001$ ) and the SES composition (Pearson $r=0.58 ; P<0.001$ ). This indicates that there is a higher futility culture in schools with a higher share of immigrant pupils and those with a higher share of pupils from a blue-collar working-class background.

\section{Results}

In order to assess whether school context matters with respect to academic achievement, the variance components for math achievement from the unconditional models should be assessed (Table 2). We are particularly interested in the variance at the school level, which is computed as the between-school variance component divided by the sum of the within-school and betweenschool variance $\left[\tau_{0} /\left(\sigma^{2}+\tau_{0}\right)\right]$. As has been found in other school-effect research (Teddlie and Reynolds, 2000) most of the variation occurs within schools and between pupils. Nevertheless, these figures indicate that a considerable amount of variance in math achievement is at school level; this justifies the need for a multilevel analysis. To be more specific, Table 2 demonstrates that for native and immigrant pupils respectively 26 per cent $(P<0.001)$ and 25 per cent $(P<0.001)$ of the variance lies between schools.

Models i1 (Table 3) and n1 (Table 4), show that the proportion of immigrant pupils at a school is negatively related to the academic performance of both immigrant pupils (standardized coefficient $\gamma^{*}=-0.199 ; P<0.01$; Model i1) and native pupils $\left(\gamma^{*}=-0.245 ; P<0.01\right.$; Model n1). In the next two models, i2 (Table 3) and n2 (Table 4), control variables at the pupil and the school level are included. For both groups, the effect of ethnic composition now drops to an insignificant level, indicating that all else being equal, the proportion of immigrant pupils at a school does not have an impact on academic achievement. Hence the negative impact of

Table 2 Variance components for math achievement from the unconditional models

Immigrants

\section{Natives}

\begin{tabular}{lll}
\hline $\begin{array}{l}\text { Between-school } \\
\text { variance } \tau_{0}\end{array}$ & $28.522^{* * *}$ & $27.766^{* * *}$ \\
$\begin{array}{l}\text { Within-school } \\
\text { variance } \sigma^{2}\end{array}$ & $85.532^{* * *}$ & $77.986^{* * *}$ \\
$\begin{array}{l}\text { Per cent Variance } \\
\text { between schools }\end{array}$ & $25.01^{* * *}$ & $26.26^{* * *}$ \\
\hline $\begin{array}{l}* * * P \\
\text { Source } \text { SIPEF-data. }\end{array}$ & & \\
\hline
\end{tabular}

ethnic composition of schools is not an independent effect, but it is most likely a selection effect: children in ethnic minority concentration schools achieve less because of their individual SES and their previous achievement.

In Models i3 (Table 3) and n3 (Table 4), we redo the analyses for the socio-economic school composition. Our results indicate that the proportion of pupils from a blue-collar background at a school is negatively related to the math performance of both immigrant pupils $\left(\gamma^{*}=-0.240 ; \quad P<0.001 ;\right.$ Model i3) and native pupils $\left(\gamma^{*}=-0.371 ; \quad P<0.001 ;\right.$ Model n3). Moreover, these figures also make clear than the correlation between SES composition and academic achievement is much higher that the correlation between ethnic composition and academic achievement. In the next two models, i4 and $\mathrm{n} 4$, we control for variables at both the student and the school levels. While the effect sizes of SES composition on their academic achievement falls for both groups, SES composition remains significantly related to math achievement for both immigrants $\left(\gamma^{*}=-0.189\right.$; $P<0.01$; Model i4) and native pupils $\left(\gamma^{\star}=-0.163\right.$; $P<0.01$; Model n4).

The main goal of this study was to assess whether pupils' sense of futility and schools' futility culture could explain the impact of ethnic and socio-economic composition on pupils' academic achievement. To provide an answer to this question, in Models i5 (Table 3) and n5 (Table 4) we investigate the mediation impact of these variables for the relation between SES composition and achievement. For immigrant pupils, both pupils' sense of futility and schools' futility culture have a significant negative impact on their math achievement. Moreover, as Model i5 demonstrates, for immigrants pupils a school's futility culture tends to have the strongest association $\left(\gamma^{*}=-0.258 ; P<0.001\right)$. Most importantly, after entering sense of futility and futility culture into the model, the effect of SES composition drops noticeably and SES composition is no longer significantly related to academic achievement $\left(\gamma^{*}=-0.017 ; P=0.867\right)$; this supports our expectation that sense of futility and futility culture account for the impact of school composition. In Model n5 (Table 4), analogous findings are made for native pupils. However, the effect of futility culture is not significant for native pupils $\left(\gamma^{*}=-0.121\right.$; $P=0.110)$.

While other variables in our models are not the primary concern of this article, it is worth mentioning that for both groups, sixth grade pupils, girls, pupils from a higher socio-economic background and pupils who did not repeat a year in the past achieve significantly better in math. Native pupils also perform significantly better in private than in public schools, 
Table 3 Results of multilevel analysis for math achievement for immigrant pupils

\section{Model i1: ethnic composition}

Model i2:

ethnic composition + controls
Model i3:

SES

composition
Model i4:

SES composition + controls
Model i5: SES composition + controls + futility

School level

Ethnic composition (per cent immigrants)

$$
\begin{array}{lll}
\gamma & -0.061(0.022) & -0.030(0.024) \\
\gamma^{*} & -0.199^{* *} & -0.096
\end{array}
$$

SES composition: (per cent blue-collar)

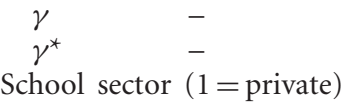

$$
\begin{array}{ccc}
\gamma & - & 0.148(1.389) \\
\gamma^{*} & - & 0.007 \\
\text { Size } & & \\
\gamma & - & -0.003(0.007) \\
\gamma^{*} & - & -0.032
\end{array}
$$

Futility culture

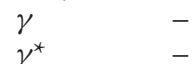

Pupil level

Grade $(1=$ sixth $)$

$$
\begin{array}{ll}
\gamma & 5.927(0.668) \\
\gamma^{*} & 0.269^{* * *}
\end{array}
$$

Gender $(1=$ girl $)$

$$
\gamma^{*}
$$

Grade retention<smiles>[Y]C1CCCC1</smiles><smiles>[3H]</smiles>

Parental support

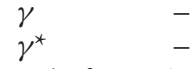

SES (ref.: service class)

Blue-collar

$$
\begin{gathered}
\gamma \\
\gamma^{*}- \\
\text { Technicians }
\end{gathered}
$$

$$
\begin{array}{ll}
\gamma & - \\
\gamma^{*} & -
\end{array}
$$

Self-employed

$$
\gamma
$$

Lower white collar

$$
\begin{array}{ll}
\gamma & - \\
\gamma^{*} & -
\end{array}
$$

Ethnicity (ref: other)

Turkish

$$
\begin{array}{cll}
\gamma & - & -2.042(0.725) \\
\gamma^{*} & - & -0.087^{\star *} \\
\text { Moroccan } & & 0.587(0.659) \\
\gamma & - & 0.026 \\
\gamma^{*} & - &
\end{array}
$$

$-0.088^{\star *}$

$-5.158(0.525)$

$-0.239^{* * *}$

$1.410(0.432)$

$-3.863(1.334)$

$-0.176^{\star *}$

$-4.179(1.505)$

$-0.136^{* *}$

-1.840 (1.536)

$-0.048$

$-1.892(1.468)$

$-0.053$

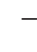

$$
\begin{aligned}
& -0.111(0.032) \\
& -0.240^{* * *}
\end{aligned}
$$

$$
-0.088(0.035)
$$$$
-0.189^{* *}
$$

$$
-0.008(0.035)
$$$$
-0.017
$$

$$
0.111 \text { (1.337) }
$$$$
0.005
$$

$$
0.092 \text { (1.124) }
$$$$
0.004
$$

-0.007 (0.007)

$-0.074$

$$
\begin{aligned}
& -0.004(0.006) \\
& -0.041
\end{aligned}
$$

-

-

$-$

$-$

$-9.773(2.564)$

$-0.258^{\star \star \star}$

$5.955(0.677)$

$0.270^{* * *}$

$5.417(0.671)$

$0.246^{* * *}$

$4.638(0.606)$

$0.210^{* * *}$

$-1.863(0.653)$

$-1.891(0.654)$

$-0.090^{* *}$

$-1.869(0.647)$

$-0.089^{* *}$

$-5.157(0.525)$

$-0.239^{* * *}$

$-4.532(0.517)$

$-0.210^{\star \star \star}$

$1.424(0.431)$

$0.628(0.434)$

0.035

$0.078^{\star * *}$

$-3.637(1.330)$

$-3.030(1.293)$

$-$

$-$

$-$

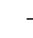

$-$

$-$

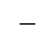

$-$

$-1.993(0.721)$

$-0.085^{\star *}$

$-1.982(0.700)$

$-0.085^{\star *}$

$0.648(0.658)$

$0.942(0.641)$ 0.042 
Table 3 Continued

\begin{tabular}{|c|c|c|c|c|c|}
\hline & $\begin{array}{l}\text { Model i1: } \\
\text { ethnic } \\
\text { composition }\end{array}$ & $\begin{array}{l}\text { Model i2: } \\
\text { ethnic } \\
\text { composition } \\
\text { + controls }\end{array}$ & $\begin{array}{l}\text { Model i3: } \\
\text { SES } \\
\text { composition }\end{array}$ & $\begin{array}{l}\text { Model i4: } \\
\text { SES } \\
\text { composition } \\
\text { + controls }\end{array}$ & $\begin{array}{l}\text { Model i5: SES } \\
\text { composition + } \\
\text { controls + futility }\end{array}$ \\
\hline \multicolumn{6}{|c|}{ Sense of futility } \\
\hline$\gamma$ & - & - & - & - & $-2.331(0.314)$ \\
\hline$\gamma^{*}$ & - & - & - & - & $-0.186^{\star * \star}$ \\
\hline \multicolumn{6}{|c|}{ Variance components } \\
\hline \multicolumn{6}{|c|}{ Between schools } \\
\hline$\tau_{0}$ & $23.869^{\star * \star}$ & $22.373^{* * *}$ & $22.265^{\star * *}$ & $20.417^{\star * *}$ & $12.864^{\star \star}$ \\
\hline \multicolumn{6}{|c|}{ Within schools } \\
\hline$\sigma^{2}$ & $79.708^{\star * *}$ & $68.058^{\star * *}$ & $79.593^{* * *}$ & $67.975^{\star * *}$ & $65.014^{\star * *}$ \\
\hline
\end{tabular}

Gamma coefficients $(\gamma)$, standardized gamma coefficients $\left(\gamma^{*}\right)$, standard errors (in parentheses) and variance components.

${ }^{*} P<0.05,{ }^{* *} P<0.01,{ }^{* *} P<0.001 ; N$ schools $=66, N$ pupils $=1206$.

Source: SIPEF-data.

while a school's sector is not significantly related to immigrant pupils' academic achievement. Regarding different immigrant groups, Turkish pupils tend to achieve less than 'other' immigrant pupils. It should also be noted that the initial positive effect of parental support, for both immigrant and native pupils, disappears after entering sense of futility and futility culture in to the models, which indicates that sense of futility does not only capture pupils' feelings acquired at school, but also those that are acquired at home.

\section{Conclusion}

This study aimed to improve our understanding of the impact of the ethnic and socio-economic composition of schools on pupils' academic achievement. More specifically, we investigated whether pupils' sense of futility and schools' futility culture mediate the effects of the ethnic and socio-economic makeup of primary schools in Flanders on math achievement.

The results of the initial multilevel analyses do indicate that the ethnic and socio-economic composition of schools are related to pupils' academic performance. Indeed, the share of immigrant pupils and the proportion of pupils from a blue-collar working-class background were found to correlate with lower math achievement among both immigrant and native Belgian pupils. However, after taking variables such as family SES and prior academic achievement into account, ethnic composition was no longer found to be significantly associated with achievement, whereas the SES composition still was. This finding is in accord with most of the other studies that have been conducted in different countries, which have shown that socioeconomic composition matters more than the ethnic composition in terms of academic achievement (Van der Slik et al., 2006; Ryabov and Van Hook, 2007; Dumay and Dupriez, 2008).

How then, should we explain the remaining impact of SES composition? We theorized that pupils' sense of futility and schools' futility culture might account for the impact of compositional school characteristics. Our empirical results support this idea. There is a significant association between the proportion of working-class pupils at school and pupils' sense of futility and futility culture. These dispositions, in turn, were found to mediate the relationship between SES composition and academic achievement. That is, after controlling for the effects of a sense of futility and futility culture, SES composition was no longer found to be related to pupils' math achievement. This holds true for both immigrant and native pupils.

Before we discuss the implication of our results, it is important to keep in mind a few weaknesses of this study. First of all, our data included only math achievement and consequently we do not have evidence on how school composition affects other achievement. However, Driessen (2002) has demonstrated that the ethnic and socio-economic makeup of the primary schools in the Netherlands have more effect on language achievement than on math achievement. Therefore, it is possible that we underestimate the impact of school composition on academic achievement. A second drawback of this study is that we only considered the influence of school-level and pupil-level variables, and failed to include any classroom-level variables. However, we did this because our sample was not suitable for running a three-level model, and the focus of the research project was on the impact of school composition. Similarly, other contexts (e.g. neighborhood, 
Table 4 Results of multilevel analysis for math achievement for native pupils. Gamma coefficients $(\gamma)$, standardized gamma coefficients $\left(\gamma^{\star}\right)$, standard errors (in parentheses) and variance components

\begin{tabular}{|c|c|c|c|c|}
\hline $\begin{array}{l}\text { Model n1: } \\
\text { ethnic } \\
\text { composition }\end{array}$ & $\begin{array}{l}\text { Model n2: } \\
\text { ethnic } \\
\text { composition } \\
\text { + controls }\end{array}$ & $\begin{array}{l}\text { Model n3: } \\
\text { SES } \\
\text { composition }\end{array}$ & $\begin{array}{l}\text { Model n4: } \\
\text { SES } \\
\text { composition } \\
\text { + controls }\end{array}$ & $\begin{array}{l}\text { Model n5: SES } \\
\text { composition + } \\
\text { controls + futility }\end{array}$ \\
\hline
\end{tabular}

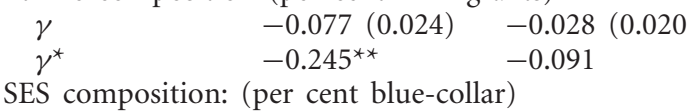

School level

Ethnic composition (per cent immigrants)

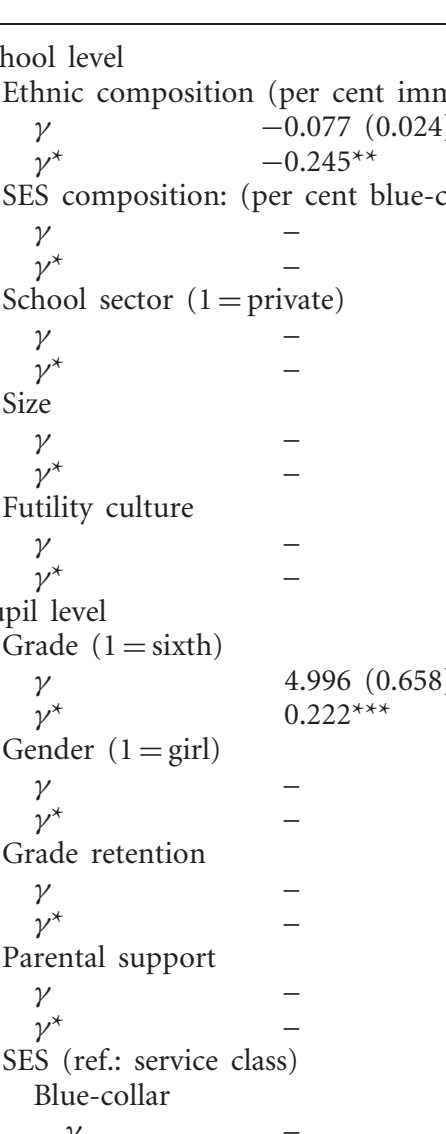

School sector $(1=$ private $)$

$\begin{array}{cc}\gamma & - \\ \gamma^{*} & - \\ \text { Size } & - \\ \gamma & - \\ \gamma^{*} & - \\ \text { Futility culture } & \\ \gamma & - \\ \gamma^{*} & -\end{array}$

Pupil level

Grade $(1=$ sixth $)$

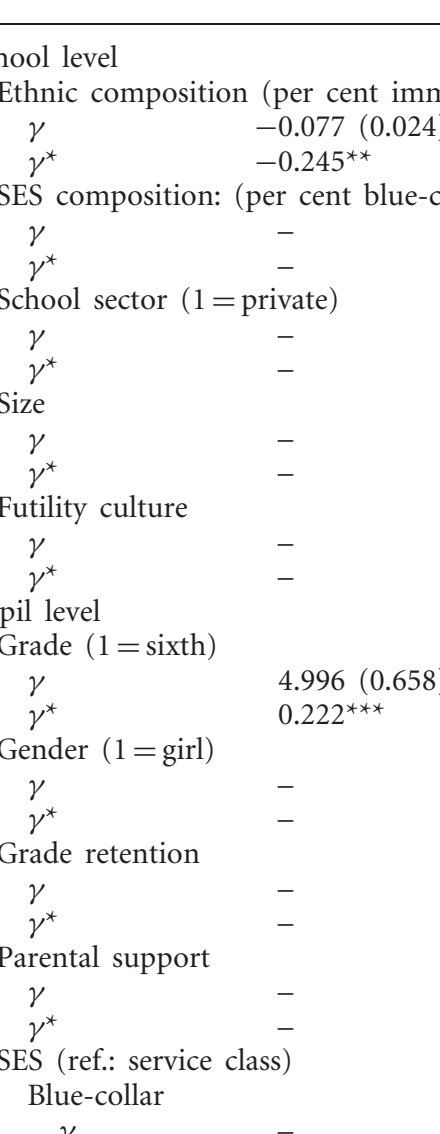

Gender $(1=$ girl $)$

$$
\gamma
$$

Grade retention

$\gamma$

Parental support

$\gamma$

$\gamma^{*}$

SES (ref.: service class)

Blue-collar

$\gamma$

$\gamma^{*}$

Technicians<smiles>[AlH]C1CC1</smiles><smiles>[Te][Te]</smiles>

Self-employed

$\gamma$ $\gamma^{*}$

Lower white collar<smiles>[Y][CH]C</smiles>

Sense of futility<smiles></smiles>

Variance components

Between schools

$\tau_{0}$ $\sigma^{2}$

$74.709^{* * *}$
-

$-0.167(0.034)$

$-0.371^{* * *}$

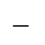

$-$

$-$

$0.008(0.005)$

0.088

$-$

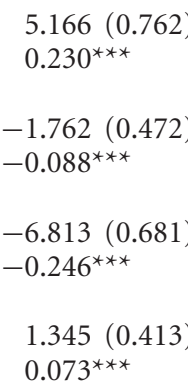

$-5.915(0.815)$

$-0.224^{* * *}$

$-4.857(0.746)$

$-0.182^{\star * *}$

$-3.902(0.958)$

$-0.093^{* * *}$

$-1.863(0.645)$

$-0.081^{\star *}$

$-$

$10.810^{*}$

$60.258^{* * *}$
$4.967(0.652)$

$0.221^{\star * *}$

$-$

$-$

$-$

$-$

$-$

$-$

-

$-$

$-$

$-$

$-$

$-$

$-$

$-$

$8.488^{* * *}$

$74.702^{* * *}$
$-$

$-0.074(0.032)$

$-0.163^{* *}$

$(0.037)$

$3.105(1.113)$

$0.156^{\star *}$

$3.394(1.023)$

$0.170^{\star \star \star}$

$0.007(0.005) \quad 0.006(0.005)$

0.071

0.068

$-4.449(2.792)$

$\begin{array}{ll}- & -4.449 \\ - & -0.121\end{array}$

$5.197(0.778)$

$0.231^{\star * *}$

$4.917(0.789)$

$0.219^{\star * \star}$

$-1.738(0.471) \quad-1.702(0.429)$

$-0.087^{* * *}-0.085^{* * *}$

$-6.774(0.688) \quad-6.252(0.699)$

$-0.245^{\star * *}$

$-0.226^{\star \star \star}$

$1.360(0.413)$

$0.161(0.412)$

$0.074^{\star * *}$

0.009

$-5.734(0.820) \quad-4.226(0.791)$

$-0.217^{* * *}-0.160^{* * *}$

$-4.750(0.753) \quad-3.771(0.743)$

$-0.178^{\star \star \star}$

$-0.142^{* * *}$

$-3.888(0.957) \quad-3.158(0.928)$

$-0.093^{\star * *} \quad-0.076^{\star * *}$

$-1.813(0.643) \quad-1.341(0.574)$

$-0.079^{\star *}$

$-0.058^{\star *}$

$-3.149(0.348)$

$-0.239^{* * *}$

2.920

$54.882^{* * *}$

${ }^{*} P<0.05,{ }^{* *} P<0.01,{ }^{* *} P<0.001 ; N$ schools $=62, N$ pupils $=1352$. 
country) might also have an impact on academic achievement (Brannstrom, 2008; Kauppinen, 2008). We suggest that future research should examine the impact of the characteristics of these contexts as well. A third potential limitation of this study is related to the cross-sectional design of our data: we could only indirectly rule out selection effects. For instance, we only had a limited measure of pupils' previous academic achievement. Future research with longitudinal data could (partly) overcome this problem.

With regard to educational policy, our study does clarify that the composition of schools matters in terms of students' academic achievement. Nevertheless, socioeconomic composition matters more than ethnic composition. However, our results indicate that even socio-economic desegregation may not be needed if it is possible to reform schools that have a higher share of working-class pupils, to become more like schools that produce more favorable dispositions. While school improvement is a difficult task, it is still feasible in the middle and the long term (Stoll and Myers, 1998). Following Bourdieu's writings on reflexivity, which is proposed as a key concept that should be deployed for social change (Bourdieu and Wacquant, 1992) we believe that reflexive education might be necessary for effective school reform. Indeed, group-based feelings such as sense of futility are likely to have an impact on academic achievement in an unreflective and subconscious manner. This means that pupils are not aware that their academic performance is influenced by their feelings. Thus a reflexive education implies that pupils become aware of these educational processes through schooling. In other words, pupils should be taught about the social determinants of their academic achievement, such as the impact of social class contexts on their feelings toward learning. However, a reflexive education should be encouraging and embrace a non-deterministic approach. This should include teaching that some pupils are in a socially disadvantaged situation, while emphasizing that, despite this, their efforts can make a difference, and that it is possible to beat the system. Such a reflexive education is a key means of decreasing pupils' sense of futility and schools' futility culture.

Nevertheless, the decision whether or not to desegregate schools should not be based solely on the criterion of educational achievement (see Agirdag, Van Houtte and Van Avermaet, 2011 for the impact of school segregation on non-cognitive outcomes in Flanders). If policy-makers do consider desegregation, such a reallocation policy should fundamentally differ from the early forced desegregation attempts in the United States, where Black students were forcibly moved to predominantly White schools. Such a policy has been shown to be fruitless and even detrimental to the educational achievement of ethnic minority students (Armor, 1995). In addition, working class and ethnic minority pupils' self-esteem have been shown to decline in middle-class schools (Gray-Little and Hafdahl, 2000). Moreover, the Belgian constitutional law prohibits any government involvement in the parental right to freedom in choosing a school. Therefore, we propose the voluntary enrollment of middle-class children (both native and immigrant children) in predominantly working-class schools. James Coleman and his team (1966) noted that high-SES students were less negatively affected by the composition of schools. An example of an appropriate practice for policy makers is a small-scale project in Flanders named 'School in Zicht.' This organization aims to unite middle-class parents (both native and immigrant) who choose to enroll their children (voluntarily) in a so called 'concentration school'. It is argued that there are many open-minded, middle-class parents who would like to enroll their children in such schools, but are afraid to do so because they believe that their children will be isolated (Albertijn and Smijers, 2009). With this in mind, 'School in Zicht' attempts to reassure parents by providing ample information about these schools and as the opportunity for parents to enroll their children together with other middle-class parents from ethnically diverse backgrounds. Given that our results point out that a higher share of middle-class pupils might increase academic achievement, a project such as 'School in Zicht' should be encouraged.

\section{Acknowledgements}

The authors would like to thank three anonymous referees for their constructive comments. Special thanks to Ward Nouwen, Paul Mahieu, Anneloes Vandenbroucke, and Simon Boone for their helpful comments.

\section{Funding}

The Research Foundation Flanders (G.040908).

\section{References}

Abedi, J., Hofstetter, C. H. and Lord, C. (2004). Assessment accommodations for English language learners: implications for policy-based empirical research. Review of Educational Research, 74, 1-28.

Agirdag, O. (2009). All languages welcomed here. Educational Leadership, 66, 20-25. 
Agirdag, O. (2010). Exploring bilingualism in a monolingual school system: insights from Turkish and native students from Belgian schools. British Journal of Sociology of Education, 31, 307-321.

Agirdag, O., Van Houtte, M. and Van Avermaet, P. (2011). Ethnic school context and the national and sub-national identifications of pupils. Ethnic and Racial Studies, doi: 10.1080/01419870.2010.510198. E-pub ahead of print 10 September 2010.

Albertijn, M. and Smeyers, M. (2009). School in zicht. Tien lessen uit drie jaar werken aan desegregatie in het onderwijs [School in Sight. Ten Lessons from Three Years Working on Desegregation in Education]. Antwerpen: Tempera.

Alexander, K. L., Entwisle, D. R. and Dauber, S. L. (1994). On the Success of Failure: A Reassessment of the Effects of Retention in the Primary Grades. Cambridge: Cambridge University Press.

Armor, D. J. (1995). Forced Justice: School Desegregation and the Law. New York: Oxford University Press.

Bankston, C. L. and Caldas, S. J. (1998). Family structure, schoolmates, and racial inequalities in school achievement. Journal of Marriage and the Family, 60, 715-723.

Biedinger, N., Becker, B. and Rohling, I. (2008). Early ethnic educational inequality: the influence of duration of preschool attendance and social composition. European Sociological Review, 24, 243-256.

Boado, H. C. (2007). Immigrant concentration in schools: peer pressures in place. European Sociological Review, 23, 341-356.

Bourdieu, P. (1977). Outline of a Theory of Practice. Cambridge: Cambridge University Press.

Bourdieu, P. and Passeron, J. C. (1990). Reproduction in Education, Society, and Culture, 2nd edn. Beverly Hills, CA: Sage.

Bourdieu, P. and Wacquant, L. J. D. (1992). An Invitation to Reflexive Sociology. Chicago: University of Chicago Press.

Brännström, L. (2008). Making their mark: the effects of neighbourhood and upper secondary school on educational achievement. European Sociological Review, 24, 463-478.

Brookover, W. B. and Schneider, J. M. (1975). Academic environments and elementary-school achievement. Journal of Research and Development in Education, 9, 82-91.

Brookover, W. B. et al. (1978). Elementary-school social climate and school-achievement. American Educational Research Journal, 15, 301-318.

Brutsaert, H. (2001). Co-educatie: Studiekansen en Kwaliteit van het Schoolleven [Coeducation: Educational
Opportunities and the Quality of School Life]. Leuven-Apeldoorn Belgium: Garant.

Coleman, J. S. et al. (1966). Equality of Educational Opportunity. Washington, DC: US Department of Health Education and Welfare Office of Education.

Driessen, G. (2002). School composition and achievement in primary education: a large-scale multilevel approach. Studies in Educational Evaluation, 28, 347-368.

Dudal, P. and Deloof, G. (2004). Vrij centrum voor leerlingenbegeleiding. Leerlingenvolgsysteem. Wiskunde: Toetsen 5 - Basisboek. Antwerpen: Garant.

Dumay, X. and Dupriez, V. (2008). Does the school composition effect matter? Evidence from Belgian data. British Journal of Educational Studies, 56, 440-477.

Erikson, R., Goldthorpe, J. H. and Portocarero, L. (1979). Intergenerational class mobility in 3 Western European societies - England, France and Sweden. British Journal of Sociology, 30, 415-441.

Fekjaer, S. N. and Birkelund, G. E. (2007). Does the ethnic composition of upper secondary schools influence educational achievement and attainment? A multilevel analysis of the Norwegian case. European Sociological Review, 23, 309-323.

Frost, M. B. (2007). Texas students' college expectations: does high school racial composition matter? Sociology of Education, 80, 43-65.

Glick, W. H. (1985). Conceptualizing and measuring organizational and psychological climate - pitfalls in multilevel research. Academy of Management Review, 10, 601-616.

Gray-Little, B. and Hafdahl, A. R. (2000). Factors influencing racial comparisons of self-esteem: a quantitative review. Psychological Bulletin, 126, 26-54.

Huisman, M. (2000). Imputation of missing item responses: some simple techniques. Quality and Quantity, 34, 331-351.

Jacobs, D., Rea, A. and Teney, C. (2009). De sociale lift blijft steken. De prestaties van allochtone leerlingen in de Vlaamse Gemeenschap en de Franse Gemeenschap [The Social Lift Stops Working. The Performance of Immigrant Pupils in the Flemish Community and the French Community]. Brussel: Koning Boudewijnstichting.

Kauppinen, T. M. (2008). Schools as mediators of neighbourhood effects on choice between vocational and academic tracks of secondary education in Helsinki. European Sociological Review, 24, 379-391.

King, G., Keohane, R. O. and Verba, S. (1994). Designing Social Inquiry: Scientific Inference in Qualitative Research. Princeton, NJ: Princeton University Press. 
Manski, C. F. (1993). Identification of endogenous social effects - the reflection problem. Review of Economic Studies, 60, 531-542.

Manski, C. F. (2000). Economic analysis of social interactions. Journal of Economic Perspectives, 14, 115-136.

Nash, R. and Lauder, H. (2010). Explaining Inequalities in School Achievement: A Realist Analysis. Farnham, Surrey: Ashgate.

Rosenberg, M. and Simmons, R. G. (1972). Black and White Self-Esteem: The Urban School Child. Washington: American Sociological Association.

Rumberger, R. W. and Palardy, G. J. (2005). Does segregation still matter? The impact of student composition on academic achievement in high school. Teachers College Record, 107, 1999-2045.

Ryabov, I. and Van Hook, J. (2007). School segregation and academic achievement among Hispanic children. Social Science Research, 36, 767-788.

Shrout, P. E. and Fleiss, J. L. (1979). Intraclass correlations - uses in assessing rater reliability. Psychological Bulletin, 86, 420-428.

Sierens, S. et al. (2006). Onderwijs onderweg in de immigratiesamenleving [Education on the Way in the Immigration Society]. Gent: Academia Press.

Singer, J. D. (1998). Using SAS PROC MIXED to fit multilevel models, hierarchical models, and individual growth models. Journal of Educational and Behavioral Statistics, 23, 323-355.

Stern, G. (1970). People in Context: Measuring PersonEnvironment Congruence in Education and Industry. New York: Wiley.

Stoll, L. and Myers, K. (1998). No Quick Fixes: Perspectives on Schools in Difficulty. London: Falmer Press.

Strand, S. (1997). Pupil progress during Key Stage 1: a value added analysis of school effects. British Educational Research Journal, 23, 471-487.

Szulkin, R. and Jonsson, J. O. (2007). Ethnic Segregation and Educational Outcomes in Swedish Comprehensive
Schools. Working Paper 2007:2. Stockholm: The Stockholm University Linneaus Center for Integration Studies (SULCIS).

Teddlie, C. and Reynolds, D. (2000). The International Handbook of School Effectiveness Research. London: Falmer Press.

Thrupp, M. (1999). Schools Making a Difference-Let's be Realistic!: School Mix, School Effectiveness, and the Social Limits of Reform. Buckingham, England; Philadelphia: Open University Press.

Thrupp, M., Lauder, H. and Robinson, T. (2002). School composition and peer effects. International Journal of Educational Research, 37, 483-504.

Van der Slik, F. W. P., Driessen, G. W. J. M. and De Bot, K. L. J. (2006). Ethnic and socioeconomic class composition and language proficiency: a longitudinal multilevel examination in Dutch elementary schools. European Sociological Review, 22, 293-308.

Van Houtte, M. and Stevens, P. A. J. (2008). Sense of futility the missing link between track position and self-reported school misconduct. Youth \& Society, 40, 245-264.

Van Houtte, M. and Stevens, P. A. J. (2009). School ethnic composition and students' integration outside and inside schools in Belgium. Sociology of Education, 82, 217-239.

Van Houtte, M. and Stevens, P. A. J. (2010). The culture of futility and its impact on study culture in technical/vocational schools in Belgium. Oxford Review of Education, 36, 23-43.

Van Maele, D. and Van Houtte, M. (2010). The quality of school life: teacher-student trust relationships and the organizational school context. Social Indicators Research, 100, 85-100.

Verkuyten, M. and Thijs, J. (2004). Global and ethnic self-esteem in school context: minority and majority groups in the Netherlands. Social Indicators Research, 67, 253-281. 